\title{
Personality Profiles Associated with Cognitive Functioning after Three Years of Follow-up in People with Schizophrenia
}

\author{
Shu Ping Chuang ${ }^{1,+}$, Jo Yung Wei Wu ${ }^{2}$, Chien Shu Wang ${ }^{3,4}$, Li Hsiang Pan ${ }^{5}$
}

\begin{abstract}
Objectives:

Personality abnormalities appear to be related to the cognitive deficits in patients with chronic schizophrenia. However, few studies have explicitly addressed the nature of the association through a longitudinal design.
\end{abstract}

\section{Method:}

Twenty-five patients with schizophrenia and age-matched with 25 healthy individuals were recruited into the study. Each participant received the big five inventory (Mini-Marker), and neuropsychological tests (WCST, go/ no go task). A follow-up was conducted three years later, and participants were asked to complete the same set of neuropsychological tests.

\section{Results:}

Correlation analysis showed that neuroticism was positively correlated with total response errors and negatively correlated with total categories completed of WCST in schizophrenia $(r=0.41, p<0.05 ; r=-0.43, p<0.05$, respectively). Conscientiousness was positively associated with the median reaction time in the go/ no go task $(r=0.44, p<0.05)$. At baseline, the healthy group scored significantly higher on extraversion and agreeableness, respectively $(p<0.001$, $\mathrm{p}<0.05$ ). The patient group showed poor performances on a majority of the WCST and go/ no go task (from $p<0.05 \sim p<0.001$ ). The scores in cognitive functioning among people with schizophrenia were significantly lower on a number of errors of go/ no go task in the followup compared to the baseline $(p<0.05)$.

\section{Conclusion:}

Our findings suggest that neuroticism and conscientiousness contributed significantly to neuropsychological deficits over time. Comprehensive neuropsychological assessments are needed to investigate the relationship between personality profiles and cognitive performances in schizophrenia over time.

\section{Keywords}

Big five personality, Cognitive functioning, Schizophrenia

\section{Introduction}

In the pathogenesis of schizophrenia, personality is considered to be one of the important factors that may impact a patient's symptoms, social functioning and subjective quality of life [1-4]. The five major personality traits of the Five-Factor

\footnotetext{
'Department of Psychiatry, Zuoying Branch of Kaohsiung Armed Forces General Hospital, Kaohsiung, Taiwan

${ }^{2}$ Good-Day Psychology Clinic, Tainan, Taiwan

${ }^{3}$ Department of Psychiatry, Kaohsiung Armed Forces General Hospital, Kaohsiung, Taiwan

${ }^{4}$ Department of Nursing, Kaomei Junior College of Health Care \& Management, Kaohsiung, Taiwan

${ }^{5}$ Department of Psychiatry, Kaohsiung Municipal Ta-Tung Hospital, Kaohsiung, Taiwan

${ }^{\dagger}$ Author for correspondence: Shu-Ping Chuang, Department of Psychiatry, Zuoying Branch of Kaohsiung Armed Forces General Hospital, No. 553, Jiunshiau Rd., Zuoying District, Kaohsiung 81342, Taiwan. Tel: 886-7-5875938; Fax: 886-7-5818816, email: xota5139@ gmail.com
} 
Model (FFM) are Neuroticism, Extraversion, Openness, Agreeableness and Conscientiousness. Individuals who are high in neuroticism are vulnerable to emotional instability and show low self-confidence; high extraversion indicates a predisposition towards social interaction; high openness is the cognitive disposition to creativity and aesthetics; high agreeableness is the tendency toward being compliant and sympathetic; high conscientiousness indicates that individuals are deliberate, efficient and competent [5-7]. These five personality traits were related with clinical characteristics in people with psychotic disorders and psychotic relapse $[7,8]$.

Past studies confirmed that the personality of people with schizophrenia differed from those without schizophrenia, even prior to the appearance of psychotic symptoms, and may predict the onset and course of the illness [8-13]. Longitudinal studies have shown that these trait personality differences were stable over time in people with schizophrenia [14,15]. Cognitive functioning was associated with various aspects of the personality dimensions in first episode and chronic schizophrenia patients $[16,17]$. Through cross-sectional study designs, previous literatures have explored the relationship between personality profiles and neuropsychological performances in schizophrenia. However, limited research was conducted to investigate whether personality profiles and neuropsychological functioning in people with schizophrenia were related or independent domains over time. Thus, the purpose of this study was to investigate whether personality contributed to the neuropsychological performance among chronic schizophrenia patients who are stable in their medication adherence. Using a three-year follow-up, we hypothesized that the patient and control groups would have distinct personality profiles, and that personality profiles would account for a statistically significant amount of neuropsychological functioning among schizophrenia patients with stable medication adherence.

\section{Methods \\ - Participants}

Patients were recruited from outpatient units at the department of psychiatry at the Zuoying Branch of Kaohsiung Armed Forces General Hospital in Taiwan. Healthy controls subjects were recruited from the local community through newspaper or online advertisements. The study protocol was reviewed and approved by the Kaohsiung Armed Forces General Hospital institutional review board. Selection criteria: patients were interviewed using the Structured Clinical Interview for DSM-IV Diagnoses [18]. Participants with acute psychotic symptoms (including mood disorders), a current substance abuse disorder, poor medication adherence and those who showed neurological disorder in the preceding year were excluded from the study. Clinical stability was defined as no acute hospitalizations or changes in medication in the previous month. All patients received regular medication. Participants in the healthy control group had no current and history of Axis I disorder and none were receiving psychiatric medication prior to participation in the study. Prior to receiving assessments, all participants gave written consent in accordance with the ethical standards set forth in the Declaration of Helsinki (1964). After 3 years of follow-up, the patients received the same set of neuropsychological variables and those who did not meet the selection criteria were excluded.

\section{Measurement}

\section{- The big five inventory (Mini-Marker)}

The 40-item adjectives were constructed to assess five personality dimensions, and participants were asked to describe themselves accordingly as accurately as possible. It includes five dimensions of personality: extraversion, agreeableness, conscientiousness, neuroticism, and openness. Participants are required to score from 1 (extremely inaccurate) to 9 (extremely accurate). Results are taken at face value, with some values being positive and some being negative. The total score in any dimension ranged between 8 and 72 with higher scores indicating predominance of the personality dimension. The test had good reliability and validity [19].

\section{- Wisconsin card sorting test (WCST Computerized version 4: CV4)}

The WCST is originally developed to assess planning capacity, capacity of shifting cognitive strategies, and control of impulsive responses in reaction to environmental changes. Participants have to match a target card with one of four category cards, in which the stimuli are multidimensional according to color $(\mathrm{C})$, shape $(\mathrm{S})$ and number $(\mathrm{N})$, each dimension defining a sorting rule. After each trial, the participant 
Personality Profiles Associated with Cognitive Functioning after Three Years of Follow-up in People with Research Schizophrenia

has to settle a preordained sorting rule given just the feedback ("Right" or "Wrong"), indicating whether they have matched the card appropriately. The rule changes after 10 consecutive correct sorts. There are unannounced shifts in the sorting principle that require the participant to change his or her approach. The test ends when the participant has achieved all rule shifts or continued with 128 cards [20].

\section{- Subtests of Test of Attentional Performance (TAP)}

TAP is a computer-driven test battery that is reliable, and a valid assessment of attention deficits in children and adults. All participants are orally instructed to perform the computerized tasks. Tests were only performed when participants made no errors during the practice trials [21].

The inhibition task (Go/No Go-Task): the task assesses the capacity to perform an appropriate reaction under time pressure and to simultaneously inhibit an inappropriate behavior response. Two forms of this test were administrated: (a) Test form "1 of 2": an upright $(+)$ and a diagonal $\operatorname{cross}(\mathrm{x})$ are presented sequentially in a pseudorandom order on the screen. The participants are instructed to press the button when the diagonal cross appears (go). When an up-right appears on the screen, participants should not press the button (no go). Reaction time, omission, and false alarm were recorded.

\section{- Statistical Analysis}

All statistical analyses were carried out using SPSS22.0 Windows (SPSS, Inc, Chicago, Illinois, USA). The Mann-Whitney $U$ test and Wilcoxon signed rank test were used to examine group differences in non-parametric variables and paired samples. To examine the potential relationships between variables, we performed Spearman's rank correlations. For all significant effects, an alpha level of 0.05 was applied.

\section{Results}

\section{- Clinical and neuropsychological characteristics}

The demographic and clinical data are summarized in Table 1. The patient group did not differ significantly from the healthy group in age. The mean age of the patient group was 41.20 years $(S D=9.32)$ and received less years of education than those in the healthy group

\begin{tabular}{|c|c|c|c|}
\hline & $\begin{array}{l}\text { Schizophrenia patients } \\
n=25\end{array}$ & $\begin{array}{l}\text { Healthy control group } \\
n=25\end{array}$ & $p$ \\
\hline & Mean \pm SD & Mean \pm SD & \\
\hline Age (years) & $41.20 \pm 9.32$ & $43.88 \pm 13.03$ & .70 \\
\hline Education (years) & $12.24 \pm 2.22$ & $15.04 \pm 2.00$ & $<.001^{* * *}$ \\
\hline Onset of illness & $23.96 \pm 7.21$ & - & \\
\hline Illness of duration & $20.72 \pm 9.10$ & - & \\
\hline \multicolumn{4}{|l|}{ Big five personality } \\
\hline Extraversion & $37.64 \pm 9.43$ & $48.24 \pm 10.05$ & $<.001^{* * *}$ \\
\hline Agreeableness & $50.28 \pm 8.41$ & $55.36 \pm 6.98$ & $.03^{*}$ \\
\hline Conscientiousness & $47.04 \pm 13.94$ & $51.92 \pm 10.51$ & .20 \\
\hline Neuroticism & $36.16 \pm 5.75$ & $33.68 \pm 6.12$ & .19 \\
\hline Openness & $45.28 \pm 9.44$ & $47.24 \pm 8.26$ & .48 \\
\hline \multicolumn{4}{|l|}{$\begin{array}{l}\text { Neurocognitive } \\
\text { performances }\end{array}$} \\
\hline \multicolumn{4}{|l|}{ Executive functioning } \\
\hline Total correct responses & $56.76 \pm 26.25$ & $71.08 \pm 9.11$ & .26 \\
\hline Total response errors & $47.84 \pm 23.11$ & $30.40 \pm 20.64$ & $.004^{* *}$ \\
\hline $\begin{array}{l}\text { Total categories } \\
\text { completed }\end{array}$ & $3.08 \pm 2.37$ & $5.24 \pm 1.42$ & $.001^{* *}$ \\
\hline Perseverative errors & $25.88 \pm 18.04$ & $14.20 \pm 9.22$ & $.006^{* *}$ \\
\hline $\begin{array}{l}\text { Trials to complete first } \\
\text { category }\end{array}$ & $21.04 \pm 18.49$ & $16.92 \pm 8.91$ & .68 \\
\hline $\begin{array}{l}\text { Percent conceptual level } \\
\text { responses }\end{array}$ & $38.80 \pm 24.51$ & $66.56 \pm 19.42$ & $<.001^{* * *}$ \\
\hline \multicolumn{4}{|l|}{ Go/no-go task } \\
\hline Number of errors & $3.64 \pm 2.88$ & $2.00 \pm 1.63$ & $.03^{*}$ \\
\hline Number of omissions & $1.08 \pm 1.93$ & $0.48 \pm 0.82$ & .47 \\
\hline $\begin{array}{l}\text { Median of reaction time } \\
\text { (in } \mathrm{msec} \text { ) }\end{array}$ & $429.84 \pm 125.65$ & $369.04 \pm 84.40$ & .26 \\
\hline${ }^{*} p<.05{ }^{* *} p<.01{ }^{* * *} p<.0$ & & & \\
\hline
\end{tabular}

$(M=12.24, \quad \mathrm{SD}=2.22)$. The healthy group scored significantly higher on extraversion and agreeableness, respectively $(\mathrm{p}<0.001, \mathrm{p}<0.05)$. Patients scored significantly lower on measures of total response errors $(\mathrm{p}<0.01)$, total categories completed errors $(\mathrm{p}<0.01)$, perseverative errors $(\mathrm{p}<0.01)$ and percent conceptual level responses scores $(\mathrm{p}<0.001)$ of WCST, as well as on the number of errors $(\mathrm{p}<0.05)$ of go/ no go task than the healthy group.

\section{- Description of neuropsychological measures in patient group over time}

As summarized in Table 2, after three years of follow-up, the patient groups scored lower on the number of errors of go/ no go task compared to the baseline, and other measures were not found to be significantly different between baseline and follow-up.

\section{- Correlations between big five personality and cognitive function}

At baseline, only neuroticism was positively associated with the number of omissions in the go/ 


\begin{tabular}{|c|c|c|c|}
\hline \multirow[t]{2}{*}{ Variables } & Baseline & 36 months & \\
\hline & Mean \pm SD & Mean \pm SD & $p$ \\
\hline \multicolumn{4}{|l|}{ Executive functioning } \\
\hline Total correct responses & $56.76 \pm 26.25$ & $66.16 \pm 614.16$ & .29 \\
\hline Total response errors & $47.84 \pm 23.11$ & $52.92 \pm 23.48$ & .36 \\
\hline Total categories completed & $3.08 \pm 2.37$ & $3.56 \pm 2.10$ & .56 \\
\hline Perseverative errors & $25.88 \pm 18.04$ & $29.52 \pm 15.04$ & .31 \\
\hline Trials to complete first category & $21.04 \pm 18.49$ & $24.96 \pm 23.55$ & .65 \\
\hline Percent conceptual level responses & $38.80 \pm 24.51$ & $43.34 \pm 23.27$ & .65 \\
\hline \multicolumn{4}{|l|}{ Go/no-go task } \\
\hline Number of errors & $3.64 \pm 2.88$ & $2.24 \pm 3.12$ & $.03^{*}$ \\
\hline Number of omissions & $1.08 \pm 1.93$ & $0.68 \pm 1.49$ & .56 \\
\hline Median of reaction time (in msec) & $429.84 \pm 125.65$ & $499.40 \pm 209.92$ & .50 \\
\hline${ }^{*} p<.05$ & & & \\
\hline
\end{tabular}

no go task and agreeableness, conscientiousness and openness were negatively associated with the number of omissions of go/ no go task. At follow-up, neuroticism was positively correlated with the total response errors and negatively correlated with the total categories completed of WCST. Conscientiousness was positively associated with the median of reaction time of go/ no go task. Nevertheless, no significant correlation was found between other personality profiles and cognitive measures at follow-up. Age, education, onset and duration of illness were not correlated with the cognitive measures at follow-up (data not shown) (Table 3).

\section{Discussion}

The study is among the first to explore the relationship between personality dimensions and neuropsychological deficits in schizophrenia over a three-year follow-up. The major finding is that among people with clinically stable schizophrenia, personality profiles uniquely contributed to neuropsychological functioning. Neuroticism and conscientiousness were the only dimensions to which cognitive functioning was statistically significant. Neuroticism was associated with the worse performances of WCST (higher total response errors and lower total categories completed). One previous study found no correlations between neuroticism and WCST performances, but extraversion was negatively associated with perseverative errors and positively correlated with categories completed in schizophrenia [22]. A larger sample sized study showed that schizophrenia with high neuroticism completed fewer WCST categories [23]. The results by Gurrera et al. [16] indicated that neuroticism was correlated with non-perseverative errors in schizophrenia. The discrepancy in these studies may result from the cross-sectional design and due to the underlying constructs of the WCST [24]. A major part of these results pointed to a two-factor component: the first factor correlated with mental flexibility and the ability to recognize concepts, including these scores: total number of correct responses, total number of errors, number of completed categories, number of perseverative errors, number of perseverative responses and conceptual level responses [24]. The second factor is associated with memory, attention and motivation, and includes these scores: failure to maintain set and number of non-perseverative errors [25,26]. Several studies supported that the performances of WCST involves a wide neural network which combines cortical and subcortical structures; each in charge of different operations that are integrated in milliseconds in the area and brain activation intensity $[27,28]$.

Conscientiousness was positively associated with the median reaction time in the inhibitory control (go/ no go task), indicating that individuals with high conscientiousness were deliberate and able to proceed with inhibitory control. However, a number of errors were not significant during the follow-up $(r=-0.24)$.

Our study did not conduct follow-ups of the personality profiles and cognitive measures in the healthy control group, thus no comparison was made between the healthy and patient group at follow-up. At baseline, the healthy group scored significantly higher on extraversion, agreeableness and reported better performances in most of the WCST and go/no go task compared to the patient group. The healthy group scored higher in conscientiousness, openness and lower in neuroticism than the patient group (the differences were not significant). Our results demonstrated consistency with previous studies [29-33].

In this study, cognitive functioning in people with schizophrenia did not significantly decline after three years of follow-up. A number of factors are probable in reducing the risk of cognitive function deterioration. Our subjects were relatively stable, less acute psychotic symptoms, middle-aged and regularly received medication. A longitudinal study of patients with schizophrenia found that older age (age $>65)$ and having a greater number of psychotic symptoms were associated with cognitive decline [34,35]. The results by El-Missiry, et al. [36] indicated 
Personality Profiles Associated with Cognitive Functioning after Three Years of Follow-up in People with Research Schizophrenia

\begin{tabular}{|c|c|c|c|c|c|}
\hline Variables & Extraversion & Agreeableness & Conscientiousness & Neuroticism & Openness \\
\hline \multicolumn{6}{|l|}{ Baseline } \\
\hline \multicolumn{6}{|l|}{ Executive functioning } \\
\hline Total correct responses & -0.03 & 0.04 & 0.01 & -0.29 & 0.22 \\
\hline Total response errors & 0.33 & 0.05 & 0.15 & 0.18 & 0.11 \\
\hline Total categories completed & -0.18 & 0.16 & 0.08 & -0.26 & 0.13 \\
\hline Perseverative errors & 0.36 & 0.22 & 0.26 & 0.14 & 0.19 \\
\hline $\begin{array}{l}\text { Trials to complete first } \\
\text { category }\end{array}$ & 0.20 & 0.04 & 0.34 & -0.07 & 0.31 \\
\hline $\begin{array}{l}\text { Percent conceptual level } \\
\text { responses }\end{array}$ & -0.20 & 0.01 & -0.06 & -0.23 & 0.05 \\
\hline \multicolumn{6}{|l|}{ Go/no-go task } \\
\hline Number of errors & -0.17 & -0.04 & -0.30 & 0.15 & -0.12 \\
\hline Number of omissions & -0.26 & $-0.44^{*}$ & $-0.44^{*}$ & $0.53^{* *}$ & $-0.39 *$ \\
\hline Median of reaction time (in msec) & 0.28 & 0.24 & 0.29 & -0.06 & 0.17 \\
\hline \multicolumn{6}{|l|}{36 months } \\
\hline \multicolumn{6}{|l|}{ Executive functioning } \\
\hline Total correct responses & -0.06 & -0.20 & 0.05 & 0.04 & 0.07 \\
\hline Total response errors & 0.02 & 0.22 & -0.10 & $0.41^{*}$ & -0.04 \\
\hline Total categories completed & -0.10 & -0.16 & -0.03 & $-0.43^{*}$ & -0.00 \\
\hline Perseverative errors & 0.05 & 0.30 & 0.04 & 0.20 & 0.00 \\
\hline $\begin{array}{l}\text { Trials to complete first } \\
\text { category }\end{array}$ & 0.17 & 0.23 & 0.11 & -0.34 & 0.33 \\
\hline $\begin{array}{l}\text { Percent conceptual level } \\
\text { responses }\end{array}$ & 0.06 & -0.27 & 0.14 & -0.37 & 0.06 \\
\hline \multicolumn{6}{|l|}{ Go/no-go task } \\
\hline Number of errors & -0.19 & -0.15 & -0.24 & 0.03 & -0.24 \\
\hline Number of omissions & -0.01 & 0.14 & -0.13 & -0.20 & -0.09 \\
\hline Median of reaction time (in msec) & 0.30 & 0.20 & $0.44^{*}$ & -0.24 & 0.21 \\
\hline${ }^{*} p<.05{ }^{* *} p<.01$ & & & & & \\
\hline
\end{tabular}

that schizophrenia patients with non-medication adherence showed significantly poorer cognitive performances than those who adhered to their medication.

\section{Limitations}

This study had a number of limitations. Sample size may be considered small by personality research standards, limiting statistical power. Our samples tended to include outpatients with relatively stable and chronic, less severe symptoms and better medication adherence. Thus caution needs to be taken when extending these findings to the general heterogeneous population. Our study did not follow-up the cognitive functioning of the healthy group, thus, the relationships between neurocognitive performances and personality abnormalities in healthy group is unclear from our study results. Neuropsychological assessment was limited in this study. Comprehensive cognitive measures are needed to investigate the association between personality variables and cognitive functioning in people with schizophrenia over time.

\section{Conclusions}

These data provided preliminary evidence that personality profiles were associated with neuropsychological performance deficits in people with schizophrenia over time. Schizophrenia patients with high neuroticism had poor cognitive flexibility and those with low conscientiousness had poor reaction time of inhibitory control.

\section{Acknowledgment}

This study was supported by the grant from Zuoying Armed Forces General Hospital, Kaohsiung, Taiwan (ZBH104-22).

\section{Disclosure}

All authors declared that this study has no competing financial interests. 


\section{References}

1. Lysaker PH, Davis LW. Social function in schizophrenia and schizoaffective disorder: associations with personality, symptoms and neurocognition. Health .Qual. Life. Outcomes 2(1), 15 (2004).

2. Couture $\mathrm{S}$, Lecomte T, Leclerc C. Personality characteristics and attachment in first episode psychosis: impact on social functioning. J. Nerv. Ment. Dis 195(8), 631639 (2007).

3. Boyette LL, Korver-Nieberg N, Meijer C, et al. Genetic Risk and Outcome of Psychosis Investigation. Quality of life in patients with psychotic disorders: impact of symptoms, personality, and attachment. J. Nerv. Ment. Dis 202(1), 64-69 (2014).

4. Compton MT, Bakeman R, Alolayan $Y$, et al. Personality domains, duration of untreated psychosis, functioning, and symptom severity in first-episode psychosis. Schizophr. Res 168(1-2), 113-119 (2015).

5. Digman J M.Personality structure: emergence of the five-factor model. Annu. Rev. Psychol 50,116-123 (1990).

6. Costa PT, McCrae RR. NEO-PI-R professional manual: revised NEO personality inventory (NEO-PI-R) and NEO five-factor inventory (NEO-FFI). Psychological Assessment Resources, Odessa, Florida (1992).

7. McCrae RR. The five-factor model: issues and applications. J. Pers 60,175-532 (1992).

8. Gleeson JF, Rawlings $D$, Jackson $\mathrm{H} J$, et al. Agreeableness and neuroticisms as predictors of relapse after first-episode psychosis: a prospective follow-up study.J. Nerv. Ment. Dis 193,160-169 (2005).

9. Dinzeo TJ, Docherty N M. Normal personality characteristics in schizophrenia: are views of the literature involving the FFM. J. Nerv. Ment. Dis195(1), 421-429 (2007).

10. Bleuler E. Dementia Praecox or the Group of Schizophrenias.International Universities Press, Inc, New York, USA (1911/1950).

11. Kraepelin E, Barclay, RM, translator. Dementia praecox and paraphrenia. The Classics of Psychiatry \& Behavioral Sciences Library, Division of Gryphon Editions, Inc, Birmingham, Alabama (1919/1989).

12. Lonnqvist J-E, Verkasalo $M$, Haukka J, et al. Premorbid personality factors in schizophrenia and bipolar disorder: Results from a large cohort study of male conscripts. J. Abnorm. I Psychol 118(2), 418423 (2009).

13. van OS J, Jones PB. Neuroticism as a risk factor for schizophrenia. Psychol. Med 31(6), 1129-1134 (2001).

14. Beauchamp MC, Lecomte T, Lecomte C, et al. Do people with a first episode of psychosis differ in personality profiles ? Schizophr. Res 85(1-3), 162-167 (2006).

15. Boyette L, Nederlof J, Meijer G, et al. Three year stability of Five-Factor Model personality traits in relation to changes in symptom levels in patients with schizophrenia or related disorder. Psychiatry. Res 229(1-2), 539-454 (2015).

16. Gurrera RJ, Nestor PG, O'Donnell BF, et al. Personality differences in schizophrenia are related to performance on neuropsychological tasks. J. Nerv. Ment. Dis 193(11), 714-721 (2005).

17. Gurrera RJ, McCarley RW, Salisbury D. Cognitive task performance and symptoms contribute to personality abnormalities in first hospitalized schizophrenia. J. Psychiatr. Res 55(1), 68-76 (2014).

18. Spitzer R, Williams J, Gibbon M, et al. Structured Clinical Interview for DSM- IV. Biometrics Research New York, USA (1994).

19. Saucier G. Mini-markers: a brief version of Goldberg's unipolar big-five markers. J. Pers. Assess 63(3), 506-516 (1994).

20. Heaton RK, Chelune GJ, Talley JL, et al. Wisconsin Card Sorting Test Manual: Revised and expanded. OdessaFL: Psychological Assessment Resources (1993).

21. Zimmermann P, Fimm B. A test battery for attentional performance. Applied neuropsychological of attention: theory, diagnosis and rehabilitation Psychology Press, 110-151, New York (2002).

22. Lysaker PH, Bell MD, Kaplan E, et al. Personality and psychosocial dysfunction in schizophrenia: the association of extraversion and neuroticism to deficits in work performance. Psychiatry. Res 80(1), 61-68 (1998).

23. Lysaker PH, Bell MD, Kaplan E, et al. Personality and psychopathology in schizophrenia: the association between personality traits and symptoms. Psychiatry 62(1), 36-48 (1999).

24. Greve KW, Ingram F, Bianchini KJ. Latent structure of the Wisconsin Card Sorting Test in a clinical sample. Arch. Clin. Neuropsychol
13(7), 597-609 (1998).

25. Fey ET. The performance of young schizophrenics and young normals on the Wisconsin Card Sorting Test. J. Consult. Psychol 15(1), 311-19 (1951).

26. Bowen FP, Kamienny RS, Burns MM, et al. Parkinsonism: Effects of levodopa treatment on concept formation. Neurology 25(8), 701-704 (1975).

27. Fernandez-Duque D, Posner MI. Brain imaging of attentional networks in normal and pathological states. J. Clin. Exp. Neuropsychol 23(1), 74-93 (2001).

28. Lie C, Specht K, Marshall J C, et al. Using fMRI to decompose the neural process underlying the Wisconsin Card Sorting Test. Neurolmage 30(3), 1038-1049 (2006).

29. Kentros M, Smith TE, Hull J, et al. Stability of personality traits in schizophrenia and schizoaffective disorder: a pilot project. J. Nerv. Ment. Dis 185(9), 549-555 (1997).

30. Gurrera RJ, Nestor PG, O'Donnell BF. Personality traits in schizophrenia: comparison with a community sample. J. Nerv. Ment. Dis 188(1), 31-35 (2000).

31. Camisa KM, Bockbrader MA, Lysaker P, et al. Personality traits in schizophrenia and related personality disorders. Psychiatry. Res 133(1), 23-33 (2005).

32. Torniainen M, Suvisaari J, Partonen T, et al. Cognitive impairments in schizophrenia and schizoaffective disorder: relationship with clinical characteristics. J. Nerv. Ment. Dis 200(4), 316-322 (2012).

33. Wang CS, Wu JYW, Chang WC, et al. Cognitive functioning correlates of selfesteem and health locus of control in schizophrenia. Neuropsychiatr. Dis. Treat 9(1), 1647-1654 (2013).

34. Dickerson F, Schroeder J, Stallings C, et al. A longitudinal study of cognitive functioning in schizophrenia: clinical and biological predictors. Schizophr. Res 156(2-3), 248-253 (2014).

35. Harvey PD, Silverman JM, Mohs RC, et al. Cognitive decline in late-life schizophrenia: a longitudinal study of geriatric chronically hospitalized patients. Biol. Psychiatry 45(1), 32-40 (1999).

36. El-Missiry A, Elbatrawy A, El Missiry M, et al. Comparing cognitive functions in medication adherent and non-adherent patients with schizophrenia. Psychiatr. Res 70(1), 106-112 (2015). 